East African Medical Journal Vol. 77 No. 9 September 2000

COLD CHAIN STATUS AT IMMUNISATION CENTRES IN ETHIOPIA

Y. Berhane, MD, MPH, Associate Professor, Department of Community Health, Faculty of Medicine, Addis Ababa University, P.O. Box 2077, Addis Ababa and M.

Demissie, MD, MPH, National Tuberculosis and Leprosy Control Programme, Ministry of Health, P.O. Box 1234, Addis Ababa, Ethiopia.

Request for reprints to: Dr. Y. Berhane, Department of Community Health, Addis Ababa University, P.O. Box 2077, Addis Ababa, Ethiopia.

\title{
COLD CHAIN STATUS AT IMMUNISATION CENTRES IN ETHIOPIA
}

\author{
Y. BERHANE and M. DEMISSIE
}

\begin{abstract}
Background: Child immunisation is among the most cost-effective ways of preventing premature child deaths, and the potency of vaccines, crucial for vaccine efficacy, is dependent on effective management of the cold chain at all levels of vaccine handling.

Objective: To assess the status of the cold chain at peripheral vaccine stores in Ethiopia.

Design: Institution based cross-sectional survey in two rural and one urban administrative areas were included in the study. Sixty seven health institutions providing static vaccination services were included in the study but cold chain system was assessed fully in only sixty four. Data were collected by interviewing health workers and by directly observing the cold chain equipment and records using structured forms.

Results: Conditions of the cold chain system were described based on 64 of the 67 centres visited, three were excluded because of non-functioning cold chain. Complete temperature record was observed in $37(57.8 \%)$ of the centres. Thermometer was not available in four $(6.3 \%)$ and thermometer reading was found to be outside the optimal range in another seven $(\mathbf{1 0 . 9 \%})$ centres. Vaccine storage in the refrigerator was not proper in $47(\mathbf{7 3 . 4 \%})$ centres. Majority of the centres had neither trained personnel nor budget for maintenance of the cold chain.

Conclusion: There is a real danger of vaccines losing their potency at these centres even if they were potent on arrival. Relevant training for those handling the cold chain, improving the maintenance conditions of refrigerators and introduction of cold chain monitoring devises are recommended.
\end{abstract}

\section{INTRODUCTION}

To save lives of millions of infants and young children dying from vaccine preventable diseases, namely tuberculosis, tetanus, whooping cough, diphtheria, poliomyelitis and measles, the Expanded Programme on Immunisation(EPI) was launched by WHO in 1974. Ethiopia, as one of the member states, adopted EPI in 1980. Achieving high coverage rates is considered as one of the parameters to measure success of immunisation programme. However, disease reduction which is the ultimate goal of EPI depends mainly on the provision of a potent vaccines to the children. Vaccine potency is ensured, among other things, by maintaining a functional cold chain system at all levels. Vaccines could lose potency easily if the cold chain breaks at any point, from the manufacturer to the vaccinee(1-4).

The cold chain system is highly sensitive to any kind of mishandling and power interruption. It is assumed to be at greatest risk, particularly in tropical countries where power supply is unreliable and facilities for its maintenance are not well developed. In these areas, it is not uncommon to observe, at any given time, between $30-50 \%$ of the refrigerators and freezers being out of order $(1,4,6)$. A study from Ghana reported that only $64 \%$ of the functioning refrigerators were maintained at temperatures required for safe vaccine storage (2).

Weaknesses in the cold chain were observed both during transportation and storage of the vaccines. Some factors contributing to weaknesses of the cold chain were delays during transportation, quality of refrigerators, method of storage, too long storage at the health unit, improper use of refrigerators, power interruption, equipment breakage, and lack of trained personnel capable of managing the cold chain $(1,3,5)$.

In Ethiopia, there are no published data regarding the cold chain system at any level. Therefore, it was imperative to conduct this study with the objective of assessing the cold chain status at peripheral health institutions.

\section{MATERIALS AND METHODS}

A cross sectional survey was conducted in Addis Ababa city, and in Kenbata-Alaba-Timbaro(KAT) and Hadiya Zones of southern Ethiopia Region. All static vaccination centres were 
assessed to ascertain the status of the cold chain. The study was conducted during November 1994 and May 1995.

The study sites were deliberately selected to cover urban and rural centres. Addis Ababa, the capital city of the country, represented the urban centres. Addis Ababa has an estimated population of three million. The KAT and Hadiya zones located in southern Ethiopia, represented rural centres. The rural zones all together were estimated to have about 1.5 million people.

The list of static centres and consent to conduct the study were obtained from the respective zonal and district health departments. The research team visited the selected centres without any prior notification. On arrival at the study sites, the purpose of the study was fully explained and consent obtained from the heads of all health institutions. Only two health institutions refused to participate in the study, no particular reason was given. The study protocol was reviewed by the Ethiopian Health Science and Technology Council.

Data were collected from 67 static immunisation centres in the study area by interviewing and direct observation. Structured and pre-tested questionnaire was used during the interview and for recording the findings of the direct observation. Data were collected by two trained public health workers experienced in the Expanded Programme on Immunisation(EPI), but had no direct working relationship with the institutions in the study area. They were trained on how to fill the interview and observation forms. They were also provided with a reference manual. The principal investigator closely observed the data collection procedures in both urban and rural centres. Data were stored and processed using Epi Info version 5 statistical computer programme.

Operational definitions: These definitions were adopted from the WHO manual(1).

Static vaccination centre: Fixed facilities offering immunisation daily or according to a fixed schedule and equipped with refrigerator.

Proper refrigerator storage: A refrigerator with adequate air circulation between the vaccine boxes, vaccine kept only on the refrigerator shelves and not in the door or bottom drawer, and no food or drink stored in the refrigerator.

Recommended temperature range: Recommended internal temperature of refrigerators is between 0 to $+8^{\circ} \mathrm{C}$.

Cold chain: A system of people and equipment which ensures potent vaccines reach the vaccinees.

Vaccine potency: The ability of a vaccine to protect from the target disease.

\section{RESULTS}

A total of 67 health institutions were visited, 11 hospitals, 20 health centres and 36 health stations (clinics). 29 of the health institutions were from rural sites and 38 from Addis Ababa.

Twenty two $(32.8 \%)$ of the 67 health institutions reported that they used to collect vaccines at intervals longer than a month. Forty nine $(73.1 \%)$ of the health institutions were located within $20 \mathrm{~km}$ radius from the nearest local vaccine store. Completely melted ice packs during transportation of vaccines were encountered by only three $(4.5 \%)$ centres. Vaccine collection intervals were significantly longer in the rural institutions (Table 1).
Table 1

Vaccine collection and transportation in Ethiopia ( $n=67$ centres)

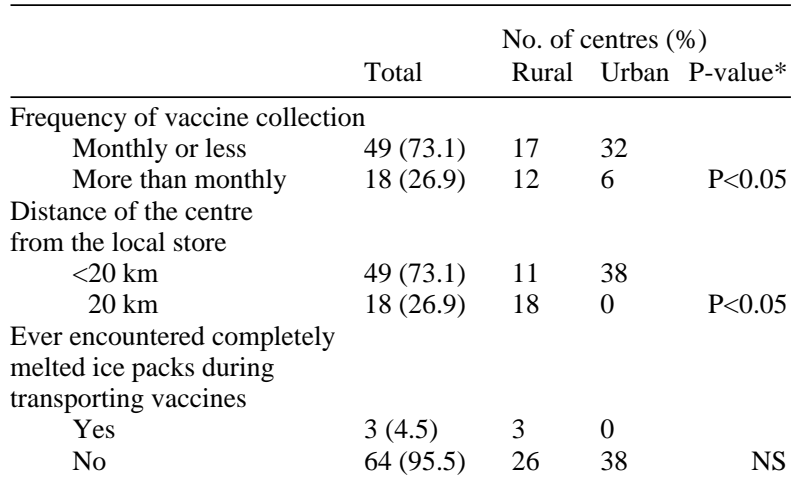

*P-value is obtained from Chi-square test. "NS" indicate a statistically insignificant difference

Major source of power for the refrigerators was electricity in all urban centres and kerosene in the majority of rural centres. Kerosene shortages were reported by nine $(42.9 \%)$ of the 21 health institutions using this form of power. Forty six $(68.7 \%)$ of the 67 centres had no experience of refrigerator break down. Period taken to get broken refrigerators fixed ranged from a few days to over a month. Though not statistically significant the rural sites took longer for refrigerators to be repaired. Lack of technicians for refrigerator maintenance and budgetary constraints were reported by $41(61.2 \%)$ and $60(89.6 \%)$ of the institutions, respectively. These problems were more pronounced in the urban centres compared to the rural ones (Table 2).

Table 2

Reported characteristics of the cold chain at the vaccination centres in Ethiopia ( $n=67$ centres).

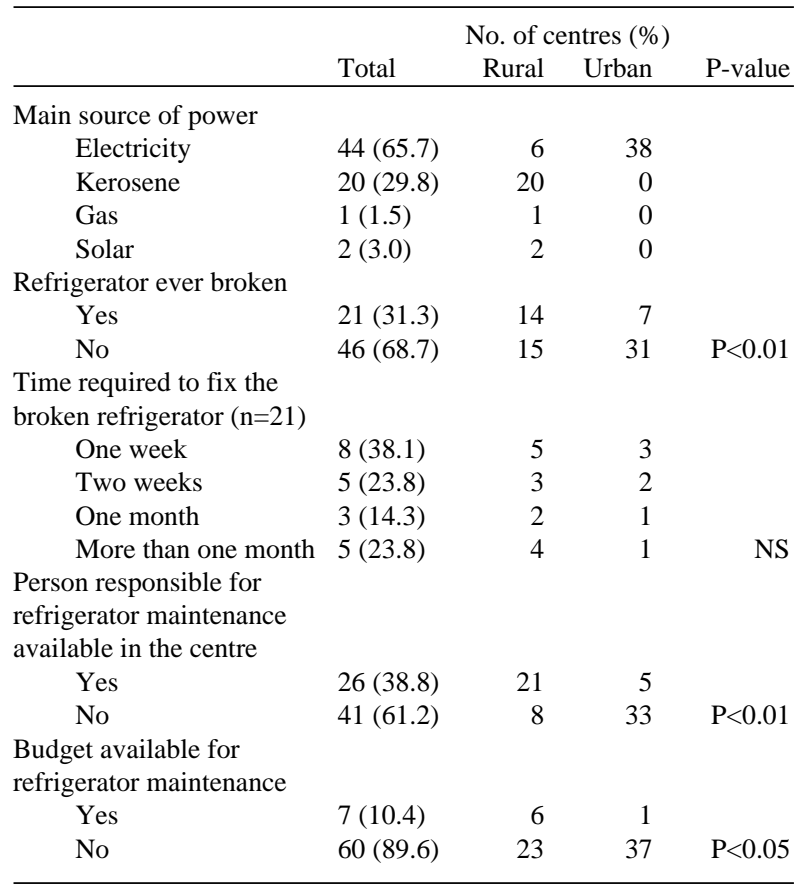

*P-value is obtained from Chi-square test. "NS" indicate a statistically insignificant difference. 
A complete record of the vaccines stock and up-todate refrigerator temperature records taken twice a day were observed in $38(59.4 \%)$ and $37(57.8 \%)$ of the 64 functional immunisation centres, respectively. Record keeping was significantly better in the urban centres. Functional freezer necessary to prepare ice packs for outreach services was available in $35(54.7 \%)$ of the functioning centres. The majority of these centres were in the rural areas. In four of the rural centres, there was no thermometer to regulate the temperature of the refrigerator, and among those found having any, seven were reading outside the recommended temperature of 0 to $+8^{\circ} \mathrm{C}$ for vaccine holding refrigerators. Temperature record keeping was significantly better in the urban centres (Table 3).

Table 3

Observed conditions of the cold chain at health institutions $*$ ( $n=64$ excluded three non-active centres).

\begin{tabular}{lrrrr}
\hline & \multicolumn{4}{c}{ No. of centres $(\%)$} \\
& Total & Rural Urban & P-value \\
\hline Vaccine stock record & & & & \\
$\quad$ Complete/updated & $38(59.4)$ & 7 & 31 & \\
Incomplete & $7(10.9)$ & 4 & 3 & \\
$\quad$ None & $19(29.7)$ & 15 & 4 & $\mathrm{P}<0.01$ \\
Daily temperature record & & & & \\
Complete/updated & $37(57.8)$ & 11 & 26 & \\
Incomplete & $19(29.7)$ & 8 & 11 & \\
$\quad$ None & $8(12.5)$ & 7 & 1 & $\mathrm{P}<0.01$ \\
Freezer working condition & & & & \\
Functional & $35(54.7)$ & 25 & 10 & \\
Not functional & $3(4.7)$ & 1 & 2 & \\
$\quad$ Not available/doesn't have & $26(40.6)$ & 0 & 26 & $\mathrm{P}<0.01$ \\
Thermometer condition & & & & \\
$\quad$ Working & $60(93.8)$ & 22 & 38 & \\
$\quad$ Not working & $4(6.2)$ & 4 & 0 & $\mathrm{P}<0.05$ \\
Thermometer reading** & & & & \\
$\quad<0$ & $1(1.7)$ & 1 & 0 & \\
$>8$ & $6(10.0)$ & 5 & 1 & \\
0-8 & $53(88.3)$ & 16 & 37 & $\mathrm{P}<0.01$ \\
Vaccine storage in the refrigerator & & & & \\
Proper & $17(26.6)$ & 12 & 5 & \\
Not proper & $47(73.4)$ & 14 & 33 & $\mathrm{P}<0.01$ \\
\hline
\end{tabular}

*Excluded three centres, two because of non-functioning refrigerator and one because there was no vaccine at the time of the survey

**Excluded four centres with non-functional thermometer

Table 4

Reasons for labelling the refrigerator as improperly stored ( $n=47$ improperly stored refrigerators)

\begin{tabular}{|c|c|c|c|c|}
\hline \multirow[b]{2}{*}{ Reason for labelling improper* } & \multicolumn{4}{|c|}{$\begin{array}{l}\text { No. of centres }(\%) \\
\text { Total Rural Urban P-value }\end{array}$} \\
\hline & & & & \\
\hline Inadequate air circulation & $21(44.7)$ & 10 & 11 & \\
\hline Water bottle not kept & $40(85.1)$ & 11 & 29 & \\
\hline Food and drink in the refrigerator & $3(6.4)$ & 2 & 1 & \\
\hline $\begin{array}{l}\text { Vaccines not kept in the proper } \\
\text { compartment }\end{array}$ & $21(44.7)$ & 5 & 16 & NS \\
\hline \multicolumn{5}{|l|}{ No. of reason per centre } \\
\hline Only one & $7(14.9)$ & 3 & 4 & \\
\hline Two or more & $40(85.1)$ & 11 & 29 & NS \\
\hline
\end{tabular}

*Multiple reasons were accepted, percents don't add up to $100 \%$
Vaccine storage in the refrigerator was observed to be improper in 47 (73.4\%) of the functioning 64 centres. Inadequate air circulation between vaccine boxes, vaccines kept in the wrong compartment of the refrigerator, and absence of water bottles in the spare space of refrigerators were the major reasons for labelling storage improper. There was no statistically significant difference regarding vaccine storage between urban and rural sites (Table 4).

\section{DISCUSSION}

Since effectiveness of the cold chain has not been widely evaluated in many developing countries including Ethiopia, the findings from this study are intended to give some insight, and can be useful to improve the cold chain system in the immunisation programmes.

Though most of the centres in this study were located within $20 \mathrm{~km}$ radius from the nearest local store, they exhibited long interval between vaccine collection periods, and long vaccine holding periods. This was attributed to shortage of transportation and lack of awareness about the negative effect of long storage at peripheral centres on vaccine potency. The longer vaccines stay at these centres the greater the danger of losing their potency(1). Though this problem was observed in both urban and rural centres, it was noted to be more serious in the rural centres. Hence, there is a need for proper training of health workers managing the programme, and ensuring the availability of adequate transportation.

From this study, it was not possible to determine the degree of exposure of vaccines to adverse temperatures, but as has been reported elsewhere(7), there are findings suggestive of this: (i) in $33 \%$ of the centres proper temperature record was not maintained; (ii) in another $11.7 \%$ of the centres thermometer reading was outside the recommended range and; (iii) in four $(6.2 \%)$ of the centre there was no functional thermometer. Therefore, even if the vaccines were potent on arrival at the health institutions, this potency could easily be compromised because of lack of proper monitoring of the cold chain system.

Problems related to the cold chain were observed in both rural and urban sites. However, some differences were observed between them: (i) vaccine storage practice and securing funds for cold chain maintenance were better in the rural sites; (ii) record keeping and temperature regulation were better in the urban sites. In general terms, except for the budgetary constraints which may require the attention of the top management, the rest of the problems are correctable by mid-level management by way of providing appropriate training to the health workers who are actually responsible for the programme, and through regular on-site supervision.

Several reports from developing countries indicate that health workers seem to be overwhelmingly concerned with only raising immunisation coverage(8-12). The quality of immunisation services that is equally important for achievement of the ultimate goal of EPI, disease reduction, has been neglected. Suboptimal seroconversion rates and 
outbreaks of vaccine preventable diseases elsewhere were attributed to loss of vaccine potency either during transportation or storage $(13,14)$.

In conclusion, this study indicated that there were real weaknesses in the cold chain system in Ethiopia, which could compromise the potency of the vaccines and the general quality of the immunisation services. Therefore, there is a need to conduct appropriate training courses for health workers managing the cold chain, and to institute supervisory mechanisms to provide on-the-job guidance and to monitor the system. Also, possibilities must be explored to introduce cold chain monitoring devices to assess the level of vaccine exposure to adverse temperature while on transportation, storage, and daily immunisation sessions.

\section{ACKNOWLEDGEMENTS}

The authors would like to acknowledge the financial support received from the Ethiopian Science and Technology Commission(ESTC). Many thanks go to the staff of all participating health institutions and health bureaus. We are grateful to the Department of Community Health for providing transport facility during the field work.

\section{REFERENCES}

1. WHO. Expanded Programme on Immunisation. Training for midlevel managers: cold chain. Revised edition. Geneva, WHO. 1989.
2. Agazi V.K. and Obuodi A.A.D. Repairing the links in Ghana's cold chain. Wld Hlth Forum. 1986; 7:345-347.

3. Lugosi L. and Battersby A. Transport and storage of vaccine in Hungary: the first cold chain monitor study in Europe. Bull. Wld Hlth Org. OMS. 1990; 68:431-440.

4. Chyne J. Strengthening the vaccine cold chain. World Health Forum. 1982; 3:436-440.

5. Population Report. Immunising the world's children. series L number 5. 1986.

6. Creese A. and Battersby A. The cost of cold chain equipment. Wld Hlth Forum. 1984; 5:165-167.

7. Simba D.O. and G. I. Msamanga. Use of cold chain to assess vaccine exposure to adverse temperatures in rural Tanzania. East Afr. Med. J. 1994; 71:445-446.

8. Silva E. Development and strategies of the Colombian vaccination program. Rev. Infect. Dis. 1989; 11:S505-S506.

9. Sorungbe, A.O.O. Expanded Programme on immunisation in Nigeria. Rev. Infect. Dis. 1989; 11:S509-S511.

10. Cutts FT. Strategies to improve immunisation services in urban Africa. Bull. Wld Hlth Organ. 1991; 69:407-414.

11. Ministry of Health. Guidelines for Expanded Programme on Immunisation in Ethiopia. Revised Version. 1988.

12. Brugha R.F. and Kevany J.P. Maximising immunisation coverage through home visits: a controlled trial in an urban area of Ghana. Bull. Wld Hlth Org. 1996; 74:517-524.

13. Nkowane B.M., Bart S.W., Orenstein W.A. and Baltier M. Measles outbreak in a vaccinated school population: Epidemiology, chains of transmission and the role of vaccine failures. Amer. J. Publ. Hlth. 1987; 77:434-438.

14. McBean A.M., Foster S.O., Herrmann K.L. and Gateff C. Evaluation of a mass measles immunisation campaign in Yaounde; Cameroon. Trans. roy. Soc. trop. Med. Hyg. 1976; 70:206-212. 